\title{
Educational inequalities in mortality due to alcoholic liver disease in Poland
}

\author{
Małgorzata Pikala', Kinga Janik-Koncewicz², Witold A. Zatoński \\ 'Department of Epidemiology and Biostatistics, Medical University of Lodz, Poland \\ Institute - European Observatory of Health Inequalities, Calisia University, Kalisz, Poland
}

\begin{abstract}
Introduction: Poland has been experiencing an epidemic of alcohol-attributable deaths in the last decades. There is a growing body of scientific evidence that educational level is linked to health behaviours and health status. The aim of the study was to analyse the impact of educational inequalities on mortality due to alcoholic liver disease (ALD) in Poland in 2002 and 2011.

Material and methods: The analysis included deaths due to alcoholic liver disease which occurred in 2002 and 2011 and information on education among Poles, aged 20 and over. Data originated from records of death certificates obtained from the database of the Central Statistical Office in Poland and the censuses. Attained educational level have been reclassified according to the International Standard Classification of Education. To assess the educational inequalities rate ratio of mortality in the group with lowest education to mortality in the group with highest education was used.

Results: The lowest risk of death due to ALD was in the group with higher education, and the highest risk was in the group with the lowest education in both men and women (i.e. standardised death rate per $100,000=0.26$ in 2002 and 0.68 in 2011 in higher educated vs 1.40 and 6.23, respectively, in lower educated women). In men, the highest risk of death from ALD was observed in the group with the lowest education aged 45-64 years (20.22/100,000 in 2002, and 44.08/100,000 in 2011). The rate ratio between 2002 and 2011 increased only in women.

Conclusions: Significant differences in deaths from alcoholic liver cirrhosis due to education have been observed in Polish adults. There is an urgent need to implement national alcohol control programs in Poland which would especially deal with alcohol consumption in the groups of population with lower education levels.
\end{abstract}

KEY WORDS: inequalities, education, Poland, alcoholic liver disease.

ADDRESS FOR CORRESPONDENCE: Witold A. Zatoński, Institute - European Observatory of Health Inequalities, Calisia University, 4 Nowy Świat St., 62-800 Kalisz, Poland, e-mail: w.zatonski@akademiakaliska.edu.pl

\section{INTRODUCTION}

Health literacy is a crucial factor in shaping individual and populational health. This concept covers a broad range of competences and skills needed to live in good health, prevent and manage diseases, and use relevant health resources and information [1]. Health competences are very significantly related to the education level of the population. Thus, health policy requires constant monitoring of the impact of education on the health status of the population [2-11].
Poland is one of the countries where the health differences resulting from education level are particularly significant [12-15]. For example, in our analyses of the relationship between education and mortality from malignant neoplasms, the level of mortality from cervical cancer in young women aged 20-44 years was one order of magnitude higher among those with lower education levels than among those with higher education levels [13]. However, observations from the recently published papers by Pikala et al. indicate that health inequalities 
have increased in the last decades in Poland [12]. The experiences of other countries indicates that these health inequalities may be avoidable [16]. Addressing these alarming phenomena in Poland requires the creation of science and evidence-based programmes. In case of Poland, the particular focus of interventions in this area should be on diseases related to tobacco smoking and alcohol consumption [17].

In Poland, the state of alcohol-related diseases is particularly critical. We have described this phenomenon in our recent publications $[18,19]$ showing the rising epidemic of alcohol attributable diseases, and especially alcoholic liver cirrhosis between 2002 and 2017. In 2015, Mackenbach et al. published a comprehensive analysis of educational inequality in alcohol-related mortality in 17 European countries, including Poland. They underlined the role of alcohol-related conditions in driving inequalities in overall mortality in many European countries and indicated that preventing alcohol-related mortality in lower socioeconomic groups is essential to reduce inequalities in mortality [20].

This paper presents an epidemiological analysis of educational inequalities in mortality due to alcoholic liver disease (ALD) in 2002 and 2011 in Poland.

\section{MATERIAL AND METHODS}

The analysis included deaths due to alcoholic liver disease (K70 - International Statistical Classification of Diseases and Related Health Problems, 10th revision code) which occurred in $2002(n=1075)$ and 2011 $(n=2903)$ and information on educational level among inhabitants of Poland, aged 20 and over. The study used unlinked cross-sectional design based on routinely collected data. The data on deaths by educational level were obtained from records of death certificates via the database of the Central Statistical Office in Poland, whereas data for population denominators for the same educational categories were retrieved from the censuses [21, 22].

In 1999 Poland has implemented codes of diseases according the $10^{\text {th }}$ Revision of International Classification of Diseases (ICD-10) where alcohol liver disease for the first time constitutes the separate code. As the last two censuses providing data on education in Poland have been conducted in 2002 and 2011, they are the subject of present analysis.

Educational categories refer to the attained educational level. The Polish educational scheme has been reclassified into three categories corresponding to the International Standard Classification of Education (ISCED) [23]: lower secondary education or less (categories $0-2$, on average $0-8$ years of education), upper secondary education (categories 3-4, on average between 9 and 12 years of education) and higher education (categories 5-6, 13 years of education and more).

Alcoholic liver disease was chosen as the best indicator of morbidity related to alcohol consumption.
Standardised death rates (SDR) were calculated using the World Standard Population (Segi standard) [24]. To assess educational inequalities, the rate ratio (RR) was used. Rate ratio is a relative measure in which we calculated the ratio of mortality in the group with lowest education to mortality in the group with highest education.

In the analysis we used three age groups: 20-44 years, 45-64 years, and 65 years and more. To allow comparison with other studies from international literature, we included in tables also additional age groups: 20-64 years, $20+$ and $0+$. We present comparison of data in 2002 and 2011.

\section{RESULTS}

In 2002, 160 women and 915 men, and in 2011650 women and 2253 men, died from ALD. Table 1 presents standardized death rates due to alcoholic liver disease in 2002 and 2011 in Poland according to sex and age groups. We observed large differences in ALD mortality rates according to educational level in both sexes. In women, the lowest SDR was found in those with higher education in the age group 20-44 (0.00/100,000 in 2002 and $0.10 / 100,000$ in 2011), and the highest in those with lowest level of education aged 45-64 years (3.23/100,000 in 2002 and 12.98/100,000 in 2011). Similarly to women, in men the lowest SDR was found in men with higher education in the youngest age group $(0.71 / 100,000$ in 2002 and 1.38/100,000 in 2011), and the highest in men with lower education aged 45-64 years (20.22/100,000 in 2002 and 44.08/100,000 in 2011). In both men and women and in all age groups, except for 65 years and older, SDRs were lower in the group with higher education, and greater in those in the lower secondary or less education category.

The highest rate ratio was found in the youngest age group (36.30 in 2011 in women, 14.15 in men in 2002 and 12.09 in men in 2011). The lowest rate ratio was found in both men and women aged 65 years and older (3.57 in 2002 and 1.81 in 2011 in men; 0.31 in 2002 and 1.30 in 2011 in women). In 2002 the rate ratio was higher in men than in women in all age groups except for 20-64 years. In 2011 the rate ratio was higher in women than men in all age groups except for 65 years and older. Generally, the rate ratio was higher in 2011 compared to 2002 in women in all age groups. In men the rate ratio was lower in 2011 compared to 2002 in all age groups except for 45-64 years.

\section{DISCUSSION}

The analysis shows that educational level has significantly affected the risk of death due to ALD in both sexes and in all age groups in Poland in the two analysed years. Generally, the lowest risk of death due to ALD was in the group with higher education, and the highest in the group with the lowest education. The exception was the group of women aged 65 years and more, in which no clear pattern was observed. Deaths from ALD in wom- 
TABLE 1. Standardized death rates due to alcoholic liver disease in 2002 and 2011 in Poland according the age groups and sex

\begin{tabular}{|c|c|c|c|c|c|c|c|c|c|c|c|c|}
\hline \multicolumn{13}{|c|}{ WOMEN } \\
\hline Age group & \multicolumn{2}{|c|}{$20-44$} & \multicolumn{2}{|c|}{$45-64$} & \multicolumn{2}{|c|}{$65+$} & \multicolumn{2}{|c|}{$20-64$} & \multicolumn{2}{|c|}{$20+$} & \multicolumn{2}{|c|}{$0+$} \\
\hline Year & 2002 & 2011 & 2002 & 2011 & 2002 & 2011 & 2002 & 2011 & 2002 & 2011 & 2002 & 2011 \\
\hline Higher & 0.00 & 0.10 & 0.90 & 2.49 & 1.24 & 1.45 & 0.32 & 1.09 & 0.43 & 1.13 & 0.26 & 0.68 \\
\hline Upper secondary & 0.51 & 0.58 & 2.27 & 9.13 & 0.72 & 3.87 & 1.14 & 4.37 & 1.09 & 4.31 & 0.66 & 2.59 \\
\hline Lower secondary or less & 2.22 & 3.63 & 3.23 & 12.98 & 0.38 & 1.88 & 2.59 & 11.50 & 2.33 & 10.38 & 1.40 & 6.23 \\
\hline Rate ratio* $^{*}$ & - & 36.30 & 3.59 & 5.21 & 0.31 & 1.30 & 8.09 & 10.55 & 5.42 & 9.19 & 5.38 & 9.16 \\
\hline \multicolumn{13}{|c|}{ MEN } \\
\hline Age group & \multicolumn{2}{|c|}{$20-44$} & \multicolumn{2}{|c|}{$45-64$} & \multicolumn{2}{|c|}{$65+$} & \multicolumn{2}{|c|}{$20-64$} & \multicolumn{2}{|c|}{$20+$} & \multicolumn{2}{|c|}{$0+$} \\
\hline Year & 2002 & 2011 & 2002 & 2011 & 2002 & 2011 & 2002 & 2011 & 2002 & 2011 & 2002 & 2011 \\
\hline Higher & 0.71 & 1.38 & 4.48 & 9.46 & 2.03 & 8.92 & 2.06 & 4.27 & 2.06 & 4.82 & 1.24 & 2.89 \\
\hline Upper secondary & 1.91 & 5.35 & 13.52 & 31.13 & 6.94 & 23.35 & 6.07 & 14.59 & 6.17 & 15.61 & 3.70 & 9.37 \\
\hline Lower secondary or less & 10.05 & 16.68 & 20.22 & 44.08 & 7.25 & 16.17 & 13.70 & 26.50 & 12.95 & 25.29 & 7.77 & 15.18 \\
\hline Rate ratio* $^{*}$ & 14.15 & 12.09 & 4.51 & 4.66 & 3.57 & 1.81 & 6.65 & 6.21 & 6.29 & 5.25 & 6.27 & 5.25 \\
\hline
\end{tabular}

*lower secondary or lower vs higher educational level

en with higher education were extremely rare, especially in young adults. In men, the highest risk of death from ALD was observed in the group with the lowest education aged 45-64 years. The mortality rate was very high in 2002 (SDR 20.22/100,000), and further increased in 2011 to $44.08 / 100,000$. The rate ratio between 2002 and 2011 increased only in women, suggesting that inequalities in ALD mortality according to educational level increased between 2002 and 2011 in women.

In our analysis, we used data on ALD (K70) deaths from the WHO mortality database according to the $10^{\text {th }}$ Revision of International Classification of Diseases (ICD-10). In the WHO mortality database, data on deaths for Poland according to the ICD-9 classification for the years 1980-1998 are presented as three-digit codes and it is hard to differentiate between particular disease entities included in the broad category of "chronic liver disease and cirrhosis". Only the introduction of the ICD-10 classification, which uses more characters, increased the number of codes available and allowed for greater coding accuracy, as well as greater efficiency in diagnosing diseases. Since the introduction of the ICD-10 in 1999 in Poland ALD has become a precisely defined disease entity. Therefore, data for Poland since 1999 enable to accurately determine the number of deaths resulting from liver diseases only exclusively caused by alcohol (K70).

Poland experienced large changes in the population structure by education level between 2002 and 2011 [22]. In $2002,29.8 \%$ of the Polish population $(28.0 \%$ of men and $31.4 \%$ of women) had primary education. In 2011, the share of people with primary education decreased by 11.5 percentage points to $18.3 \%$ ( $16.5 \%$ of men and $20.0 \%$ of women). The percentage of people with higher education increased from $9.9 \%$ in 2002 to $17.0 \%$ in 2011 .
A greater increase of 8.6 percentage points was observed in women (from $10.4 \%$ to $19.0 \%$ ). In men, the increase in people with higher education between 2002 and 2011 was 5.5 percentage points (from $9.3 \%$ to $14.8 \%$ ). Changes in educational level in the Polish population are very important limitation of our analysis and must be taken into consideration. We must remember that in every decade there are dramatic increase especially in segment with higher education.

There were other limitations in the study. A total of $0.4 \%$ of all death certificates indicating alcoholic liver disease issued in 2002 lacked data on education level, and $2.2 \%$ lacked such data in 2011. Data on the number of people in each educational group, i.e. the denominator of death rates, was obtained from the censuses in 2002 and 2011. The percentage of people with undetermined education was 2.0 in 2002 and 5.2 in 2011 [1]. Both the death certificates with missing information about education, and those for people with undetermined education given in the census were excluded from the analysis.

The magnitude of the disparity in education-related ALD mortality continues to be a very significant health problem in Europe. This problem increasingly concerns Poland and the countries of Eastern Europe. Meanwhile, in many European countries, such as Spain or Italy, these differences are narrowing.

The available literature includes a significant number of studies analysing the problem of deaths due to ALD by education and social status [20,25-32]. The seminal study covering almost 17 European countries by Mackenbach et al. published in 2015 [20] shows that inequalities in access to education significantly affect the overall mortality, and especially the mortality due to alcohol-related diseases, including alcohol cirrhosis, which is the best epidemiological indicator of alcohol consumption. 
At the same time, Mackenbach et al. points out that there are also countries in Europe that are successful in controlling mortality due to ALD, such as France, Switzerland, Spain and Italy. Researchers indicate that what has happened in recent decades in these countries can greatly help in the development of evidence-based policy in other European countries. Poland is a country in which the development and implementation of a national alcohol control program, also based on the experience of other European countries, is particularly urgent.

\section{CONCLUSIONS}

Significant differences in deaths from alcoholic liver cirrhosis due to education have been observed in the Polish adult population. These differences are much higher in Poland than in Western European countries (i.e. Spain, Austria, or Norway) and similar to differences in neighbouring countries (i.e. Lithuania, Latvia, Estonia) [20]. Level of differences in death rates from alcoholic liver cirrhosis in some Western European countries is declining but in Poland and neighbouring countries is increasing. There is an urgent need to implement national alcohol control programs in Poland which would especially deal with alcohol consumption in groups of population with lower education levels.

\section{ACKNOWLEDGEMENTS}

Authors of the manuscript would like to thank the National Statistical Office (especially Dorota Szałtys, Agnieszka Zgierska and Piotr Olczyk), and professor Janusz Szymborski for collaboration and data release.

\section{DISCLOSURE}

The authors report no conflict of interest.

\section{References}

1. Janik-Koncewicz K, Herbeć A, Zatoński M, et al. Building health literacy in a Polish region: protocol for the POWER project in Lower Silesia. J Health Inequal 2018; 4 (1): 27-30.

2. Eriksen S. Alcohol as a gender symbol. Scand J Hist 1999; 24 (1): 45-73.

3. Federico B, Mackenbach JP, Eikemo TA, et al. Educational inequalities in mortality in northern, mid and southern Italy and the contribution of smoking. J Epidemiol Community Health 2013; 67 (7): 603-609.

4. Holmes J, Meng Y, Meier PS, et al. Effects of minimum unit pricing for alcohol on different income and socioeconomic groups: a modelling study. Lancet 2014; 383 (9929): 1655-1664.

5. Kuntsche E, Rehm J, Gmel G. Characteristics of binge drinkers in Europe. Soc Sci Med 2004; 59 (1): 113-127.

6. Mackenbach JP, Kunst AE. Measuring the magnitude of socio-economic inequalities in health: an overview of available measures illustrated with two examples from Europe. Soc Sci Med 1997; 44 (6): 757-771.
7. Marmot M, Allen J, Bell R, et al. WHO European review of social determinants of health and the health divide. Lancet 2012; 380 (9846): 1011-1129.

8. Meier PS, Holmes J, Angus C, et al. Estimated effects of different alcohol taxation and price policies on health inequalities: a mathematical modelling study. PLoS Med 2016; 13: e1001963.

9. Muller A. Education, income inequality, and mortality: a multiple regression analysis. BMJ 2002; 324 (7328): 23-25.

10. Regidor E, Kunst AE, Rodriguez-Artalejo F, Mackenbach JP. Small socio-economic differences in mortality in Spanish older people. Eur J Public Health 2012; 22 (1): 80-85.

11. Sulkunen P. Drinking in France 1965-1979. An analysis of household consumption data. Br J Addict 1989; 84 (1): 61-72.

12. Pikala M, Burzyńska $M$, Pikala $R$, et al. Educational inequalities in premature mortality in Poland, 2002-2011: a population-based cross-sectional study. BMJ Open 2016; 6: e011501.

13. Wojtyła C, Słabuszewska-Jóźwiak A, Janik-Koncewicz K, Zatoński WA. New challenges for cervical cancer. J Health Inequal 2016; 2 (1): 77-88.

14. Zatoński WA, Tukiendorf A, Zatoński M, et al. Lung cancer mortality decline among middle-aged men and women in Poland and the UK. J Health Inequal 2017; 3 (2): 123-126.

15. Zatoński WA, Zatoński M, Janik-Koncewicz K, et al. Hundred years of cigarette smoking in Poland: three phases of the tobacco epidemic. J Health Inequal 2017; 3 (2): 118-122.

16. Stirbu I, Kunst AE, Bopp M, et al. Educational inequalities in avoidable mortality in Europe. J Epidemiol Community Health 2010; 64 (10): 913-920.

17. Zatoński WA. One hundred years of health in Poland. J Health Inequal 2019; 5 (1): 11-19.

18. Zatoński WA, Zatoński MZ, Janik-Koncewicz K, McKee M. Alcohol-related liver cirrhosis in Poland: the reservoir effect. Lancet Gastroenterol Hepatol 2020; 5 (12): 1035.

19. Zatoński WA, Janik-Koncewicz K, Zatoński M, Wojtyła A. Pogorszenie stanu Zdrowia Polaków po 2002 r. Epidemia zgonów alkoholowych [Deterioration of the health of Poles after 2002. An epidemic of alcohol-attributable deaths]. Menedżer Zdrowia 2020; 7-8: 118-123.

20. Mackenbach JP, Kulhánová I, Bopp M, et al. Inequalities in alcohol-related mortality in 17 european countries: a retrospective analysis of mortality registers. PLoS Med 2015; 12 (12): e1001909.

21. Central Statistical Office. Local database. Available from: www. stat.gov.pl (accessed: 16 August 2020).

22. Ludność. Stan i struktura demograficzno-społeczna. Narodowy Spis Powszechny Ludności i Mieszkań 2011 [Population. Demographic and social condition and structure. National Census of Population and Housing 2011]. Główny Urząd Statystyczny, Warszawa 2013.

23. International Standard Classification of Education ISCED 2011. Available from: http://uis.unesco.org/sites/default/files/ documents/international-standard-classification-of-education-isced-2011-en.pdf (accessed: 16 October 2020).

24. Ahmad OB, Boschi-Pinto C, Lopez AD, et al. Age standardization of rates: a new WHO standard. Available from: https://www. who.int/healthinfo/paper31.pdf (accessed: 17 October 2020). 
25. Hemström O. Alcohol-related deaths contribute to socioeconomic differentials in mortality in Sweden. Eur J Public Health 2002; 12 (4): 254-262.

26. Leinsalu M, Vågerö D, Kunst AE. Estonia 1989-2000: enormous increase in mortality differences by education. Int J Epidemiol 2003; 32 (6): 1081-1087.

27. Mäkelä P. Alcohol-related mortality as a function of socio-economic status. Addiction 1999; 94 (6): 867-886.

28. Najman JM, Williams GM, Room R. Increasing socioeconomic inequalities in male cirrhosis of the liver mortality: Australia 1981-2002. Drug Alcohol Rev 2007; 26 (3): 273-278.

29. Norström T, Romelsjo A. Social class, drinking and alcoholrelated mortality. J Subst Abuse 1998; 10 (4): 385-395.

30. Probst C, Roerecke M, Behrendt S, Rehm J. Gender differences in socioeconomic inequality of alcohol-attributable mortality: A systematic review and meta-analysis. Drug Alcohol Rev 2014; 34 (3): 267-277.

31. Probst C, Roerecke M, Behrendt S, Rehm J. Socioeconomic differences in alcohol-attributable mortality compared with all-cause mortality: a systematic review and meta-analysis. Int J Epidemiol 2014; 43 (4): 1314-1327.

32. Sandoval JS, Leão T, Theler JM, et al. Alcohol control policies and socioeconomic inequalities in hazardous alcohol consumption: a 22-year cross-sectional study in a Swiss urban population. BMJ Open 2019; 9 (5): e028971.

\section{AUTHORS' CONTRIBUTIONS}

WZ and KJK prepared the concept of the paper. MP analysed data. WZ, MP and KJK interpreted data and wrote the draft manuscript. All authors took part in preparation the final version of the manuscript. 